\title{
Temperature Dependent Impedance Spectroscopy and Thermally Stimulated Depolarization Current (TSDC) Analysis of Disperse Red 1-co-Poly(methyl methacrylate) Copolymers
}

\author{
Yee Song Ko ${ }^{\mathrm{ab}}$, Eduardo Cuervo-Reyes ${ }^{\mathrm{cd}}$, Frank A. Nüesch ${ }^{\mathrm{ab}}$, Dorina M. Opris ${ }^{\mathrm{a}}$ \\ ${ }^{a}$ Swiss Federal Laboratories for Materials Science and Technology Empa, Laboratory for Functional \\ Polymers, Überlandstr. 129, CH-8600, Dübendorf, Switzerland; ${ }^{b}$ Ecole Polytechnique Federale de \\ Lausanne (EPFL), Institut des materiaux, Station 12, CH 1015, Lausanne, Switzerland; ${ }^{\mathrm{c}}$ Swiss \\ Federal Laboratories for Materials Science and Technology Empa, Laboratory for Reliability, \\ Science and Technology, Überlandstr. 129, CH-8600, Dübendorf, Switzerland; ${ }^{\mathrm{d}}$ Swiss Federal \\ Institute of Technology (ETH), CH-8093 Zürich, Switzerland
}

\begin{abstract}
The dielectric relaxation processes of polymethyl methacrylates that have been functionalized with Disperse Red 1 (DR1) in the side chain (DR1-co-MMA) were studied with temperature dependent impedance spectroscopy and thermally stimulated depolarization current (TSDC) techniques. Copolymers with dipole contents which varied between $10 \mathrm{~mol} \%$ and $70 \mathrm{~mol} \%$ were prepared. All samples showed dipole relaxations above the structural-glass transition temperature $\left(T_{g}\right)$. The $\beta$-relaxation of the methyl methacrylate (MMA) repeating unit was most visible in DR1(10\%)-coMMA and rapidly vanishes with higher dipole contents. DSC data reveal an increase of the $T_{g}$ by $20{ }^{\circ} \mathrm{C}$ to $125^{\circ} \mathrm{C}$ with the inclusion of the dipole into the polymethyl methacrylate (PMMA) as side chain. The impedance data of samples with several DR1 concentrations, taken at several temperatures above $T_{g}$, have been fitted with the Havriliak-Negami (HN) function. In all cases, the fits reveal a dielectric response that corresponds to power-law dipolar relaxations. TSDC measurements show that the copolymer can be poled, and that the induced polarization can be frozen by lowering the temperature well below the glass transition. Relaxation strengths $\Delta \varepsilon$ estimated by integrating the depolarization current are similar to those obtained from the impedance data, confirming the efficient freezing of the dipoles in the structuralglass state.
\end{abstract}

Keywords: Disperse Red 1, TSDC, impedance spectroscopy, PMMA, dielectric relaxation, poling

\section{INTRODUCTION}

Electro-optical polymers have been a subject of considerable interest for some time now, due to their potential application as electro-optical modulators, electro-optical switches, signal processing units and polarization controllers. ${ }^{1-5}$ In order to utilize the special properties of electro-optical polymers they first have to be poled in an electric field at temperatures around $T_{g}$ to orient the dipolar units. ${ }^{6,7}$
DR1
DR1MA
DR1-co-MMA
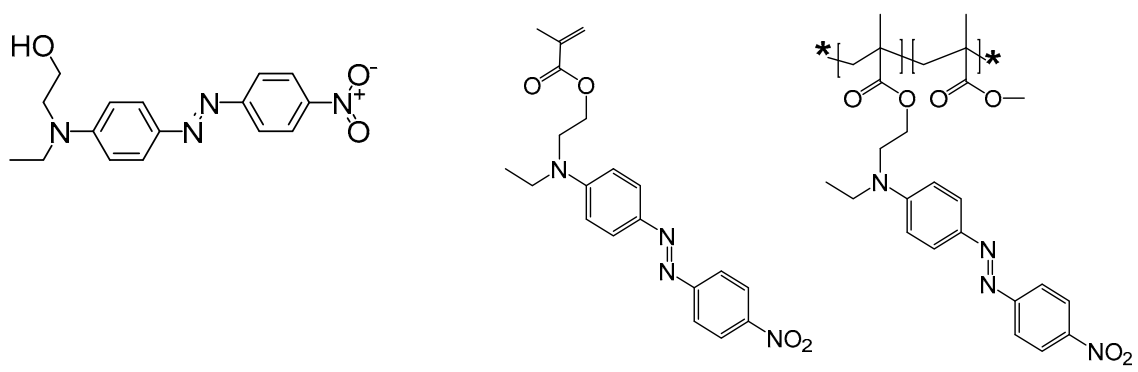

Figure 1. Chemical structure of DR1, DR1MA and DR1-co-MMA.

*dorina.opris@empa.ch; phone +41 58765 4304; www.empa.ch

Electroactive Polymer Actuators and Devices (EAPAD) 2016, edited by Yoseph Bar-Cohen, Proc. of SPIE Vol. 9798, 97981I · C 2016 SPIE · CCC code: 0277-786X/16/\$18 · doi: 10.1117/12.2218803 
A standard material in this field is a guest-host system of 4-[ethyl (2-hydroxyethyl) amino]-4-nitrobenzene, shown in Figure 1 and usually called DR1, embedded in PMMA which has been widely characterized due to its ease of preparation. ${ }^{8-11}$ There are a number of drawbacks to this system which include a fast relaxation once it has been poled, a plasticizing effect of the dipole on the matrix which lowers the $T_{g}$ of the system, and the limited amounts of dipole which can be incorporated into PMMA. ${ }^{10}$

Initially a polymer containing DR1 was thought to be attractive for other work in our lab as a reference material because of the wealth of data available, if the drawbacks can be addressed. By integrating the dipole, either as a sidechain or into the backbone of the host-polymer, the performance of electro-optical polymers can be increased drastically, ${ }^{6,12}$ such as is the case when DR1 is integrated into PMMA as a sidechain to give the copolymer DR1-co-MMA seen in Figure 1. These copolymers are commercially available at selected dipole contents and can easily be synthesized to incorporate any concentration of dipole using a DR1 molecule modified with a methacrylate group (DR1MA), also shown in Figure 1. The copolymer has been investigated many times in literature by other authors with different techniques, ${ }^{9,13,14}$ but a comprehensive study using broadband impedance spectroscopy as a function of temperature and dipole content seems to be lacking as of yet. The impedance data is presented here as complementing the previous observations. TSDC measurements were employed to confirm the poleability of the copolymers and, together with the impedance data, to evaluate the influence of the dipole content on the relaxation strength, and the thermal stability of the system.

\section{EXPERIMENTAL PART}

\subsection{Materials}

All chemicals were purchased from Sigma Aldrich and used as received. Solvents were purified and dried by standard procedures. Indium tin oxide (ITO) coated glass plates were procured from Geomatec. (Sheet resistance $20 \mathrm{Ohms}$ square $^{-1}$ ) and were consecutively cleaned in acetone, ethanol, detergent and deionised water by a sonicator bath.

\subsection{Characterization}

${ }^{1} \mathrm{H}-\mathrm{NMR}$ spectra were recorded on a Bruker Avance-400 spectrometer (400 MHz at room temperature). Gel permeation chromatography (GPC) measurements in tetrahydrofuran eluent were done with an Agilent 1100/PSS WinGPC 8.1 system calibrated with PMMA standards (Polymer Standards Service). Two columns (100, $1000 \AA$ pore size SDV-Gel) and a flow rate of $1 \mathrm{ml} \mathrm{min}{ }^{-1}$ were used. Signals were detected with a UV and IR detector. DSC measurements were performed on a Perkin Elmer DSC 8000. The DSC cycle consisted of two heating steps from $20{ }^{\circ} \mathrm{C}$ to $200{ }^{\circ} \mathrm{C}$ and a cooling step from $200{ }^{\circ} \mathrm{C}$ to $20^{\circ} \mathrm{C}$ at a rate of $20^{\circ} \mathrm{C} \mathrm{min}^{-1}$. Film thicknesses on ITO/glass substrates were measured with a Ambios Technology XP 1 profilometer.

\subsection{Synthesis and sample preparation}

DR1-co-MMA was synthesized using standard methods which are described in literature. ${ }^{13}$ First DR1 was modified with a methacrylate group by slowly adding freshly distilled methacryloyl cholride ( $4.6 \mathrm{~g})$ to an ice-cooled solution of DR1 $(10 \mathrm{~g})$ and distilled triethylamine $(5 \mathrm{~g})$ in dry dichloromethane $(27 \mathrm{ml})$ under argon atmosphere. The ice bath was removed an hour after methacryloyl chloride was added and the solution was left to react overnight. The solution was washed with brine and DR1MA was isolated by column chromatography (Ethyl Acetate 20\%, Hexane 80\%) to give a yield of $93 \%$.

Table 1. Reaction conditions and reagent amounts for synthesis of DR1-co-MMA. PD/M is the is the ratio of dipole to total repeating units and $\mathrm{M} / \mathrm{AIBN}$ is the target number of repeating units per copolymer.

\begin{tabular}{|c|c|c|c|c|c|c|c|c|}
\hline \multirow[t]{2}{*}{ Name } & \multicolumn{2}{|c|}{ Conditions } & \multirow{2}{*}{$\begin{array}{c}\text { MMA } \\
{[\mathrm{ml}]}\end{array}$} & \multicolumn{2}{|c|}{ DR1MA } & \multicolumn{2}{|c|}{ AIBN } & \multirow{2}{*}{$\begin{array}{c}\text { DMF } \\
{[\mathrm{ml}]}\end{array}$} \\
\hline & $\mathbf{t}[\mathbf{h}]$ & $\mathbf{T}\left[{ }^{\circ} \mathbf{C}\right]$ & & [mg] & DP/M & [mg] & M/AIBN & \\
\hline DR1(10\%)-co-MMA & 233 & 90 & 0.6 & 200 & 0.08 & 12 & 89 & 3.0 \\
\hline DR1(20\%)-co-MMA & 48 & 90 & 1.5 & 1600 & 0.23 & 38.4 & 78 & 7.5 \\
\hline DR1(30\%)-co-MMA & 72 & 90 & 0.9 & 1230 & 0.28 & 23.1 & 83 & 4.5 \\
\hline DR1(40\%)-co-MMA & 48 & 90 & 0.9 & 2141.6 & 0.41 & 49.3 & 45 & 7.8 \\
\hline DR1(50\%)-co-MMA & 144 & 90 & 0.6 & 2296.5 & 0.50 & 52.5 & 38 & 8.5 \\
\hline DR1(70\%)-co-MMA & 68 & 90 & 0.3 & 2673.3 & 0.70 & 62 & 26 & 9.8 \\
\hline
\end{tabular}


To obtain the copolymer, DR1MA was added to a $10 \mathrm{ml}$ schlenk-flask and the flask was thoroughly dried under vacuum with the help of a heat-gun. After drying, the flask was flooded with argon. Azobisisobutyronitrile (AIBN) was added and then capped with a septum trough which N,N-dimethylformamide (DMF) and MMA were inserted via syringe. The solution then underwent three freeze-pump-thaw-cycles followed by rigorous bubbling by argon for 30 minutes. The reaction was started afterwards by heating the solution to $90{ }^{\circ} \mathrm{C}$. Reaction times and reagent amounts can be seen in Table 1.

The reaction was terminated by bringing the solution to room temperature, adding the same amount of DMF as already in the solution and precipitating the solution into 5 times the amount of methanol. The copolymer was collected using a $0.45 \mu \mathrm{m}$ pore-size Nylon membrane filter, rinsed with deionised water on the filter and dried.

\subsection{Impedance spectroscopy}

For the temperature dependent impedance spectroscopic measurements, a Novocontrol high impedance Alpha Analyzer was used with the standard BDS 1200 sample cell and Quatro Cryosystem temperature controler. The copolymers were pressed to $25 \mathrm{mg}$ pellets which were heated to $185^{\circ} \mathrm{C}$ and pressed between two metal electrodes with three $100 \mu \mathrm{m}$ glass fibres as spacer in between. The final thickness of the samples was verified with a Heidenhain thickness measuring gauge. Impedance spectra were obtained at selected intervals between $20^{\circ} \mathrm{C}$ to $190^{\circ} \mathrm{C}$ from $0.5 \mathrm{~Hz}$ to $1 \mathrm{MHz}$. DR1(70\%)co-MMA still contained a bit of solvent (Figure 2) and was dried at $160^{\circ} \mathrm{C}$ and $0.01 \mathrm{mBar}$ overnight after the pellet was pressed to remove the solvent residue.

\subsection{Thermally stimulated depolarization current (TSDC)}

For TSDC measurements the copolymers were spincoated onto ITO/glass substrates at a speed of 1000-3000 rpm, from either a $10 \mathrm{wt} \%$ dimethylacetamide solution or a $10 \mathrm{wt} \%$ trichloropropyl solution passed through a $0.45 \mu \mathrm{m}$ pore size syringe filter. The samples were dried in a vacuum oven at 0.01 mbar and $130{ }^{\circ} \mathrm{C}$ for at least $8 \mathrm{~h}$ to remove residues of solvent. After drying, a $40 \mathrm{~nm}$ thick circular layer of silver with a diameter of $3 \mathrm{~mm}$ was evaporated onto the film. The copolymers were poled at $120^{\circ} \mathrm{C}$ for 10 min with a Keithley 2400 , after which they were cooled to RT with the field still on, at a rate of $-4^{\circ} \mathrm{C} / \mathrm{min}$. The field-strength was $30 \mathrm{~V} / \mu \mathrm{m}$. The choice of the poling temperature was guided by studies showing the ideal poling temperature being slightly below $T_{g} .{ }^{6,7,11,15}$ Temperature control was facilitated by a Lauda RC6 $\mathrm{CP}$ thermostatic oil bath connected to a closed glass container. A heating rate of $4^{\circ} \mathrm{C} / \mathrm{min}$ was chosen and measured on a reference glass substrate by a K-type thermocouple connected to a Keithley 2400 . For the actual measurement of the short circuit TSD currents a Stanford Research Systems SR570 low noise current preamplifier was used and the signal recorded with a Keithley 2000.

\section{RESULTS AND DISCUSSION}

\subsection{Basic characterization}

Conversion, dipole fraction, molecular weight $\left(M_{w}\right)$, polydispersity (PDI) and $T_{g}$ were measured for the copolymers, the results of which can be seen in Table 2 .

Table 2. Conversion, dipole fraction, molecular weight, polydispersity index and glass transition temperature of DR1-coMMA copolymers.

\begin{tabular}{|c|c|c|c|c|c|}
\hline Name & $\begin{array}{c}\text { Conversion } \\
\text { [NMR, \%] } \\
\end{array}$ & $\begin{array}{c}\text { Dipole fraction } \\
\text { [NMR, \%] } \\
\end{array}$ & $\begin{array}{c}M_{w} \\
{[\mathrm{GPC}, \mathrm{g} / \mathrm{mol}]}\end{array}$ & $\begin{array}{c}\text { PDI } \\
\text { [GPC] }\end{array}$ & $\begin{array}{c}T_{g} \\
{\left[\mathrm{DSC},{ }^{\circ} \mathrm{C}\right]}\end{array}$ \\
\hline DR1(10\%)-co-MMA & 91.62 & 9.00 & $15^{`} 000$ & 1.96 & 122 \\
\hline DR1(20\%)-co-MMA & 89.25 & 22.69 & $19^{\prime} 000$ & 1.73 & 123 \\
\hline DR1(30\%)-co-MMA & 95.39 & 28.11 & $200^{\prime} 000$ & 2.80 & 126 \\
\hline DR1(40\%)-co-MMA & 92.87 & 43.13 & $14^{\prime} 000$ & 2.41 & 121 \\
\hline DR1(50\%)-co-MMA & 96.08 & 49.85 & $17^{\prime} 000$ & 1.98 & 124 \\
\hline DR1(70\%)-co-MMA & 94.62 & 75.62 & $12^{\prime} 000$ & 2.26 & 121 \\
\hline
\end{tabular}

The ${ }^{1}$ H-NMR spectra in Figure 2 confirm the successful synthesis of the copolymers with conversions higher than $90 \%$ and a good fit between the targeted and obtained dipole fractions. The conversion was calculated from the ratio of vinyl 
peaks to the peaks corresponding to E and F,J,G in Figure 2, using ${ }^{1} \mathrm{H}-\mathrm{NMR}$ spectra of aliquots taken right before the copolymer was precipitated into methanol. The most egregious deviation from the targeted dipole fractions was the copolymer with the highest dipole content DR1(70\%)-co-MMA, which deviated by around 5 mol\%. Signals corresponding exclusively to the dipole increase with increasing target dipole content, when the signal strength is normalized by the backbone.

GPC was used to determine the molecular weight, as well as the PDI of the copolymers. The molecular weights are all in the same order of magnitude but still vary from $12^{\prime} 000$ to $21^{\prime} 000 \mathrm{~g} / \mathrm{mol}$ without any clear correlation to dipole content or reaction conditions. The PDI is generally high, between 1.9 and 2.8 , which is expected from a free radical polymerization.

The DSC measurements on the copolymers reveal a consistent increase of the $T_{g}$ from of $105{ }^{\circ} \mathrm{C}$ for PMMA ${ }^{16}$ to above $120{ }^{\circ} \mathrm{C}$ for the copolymer. A previous investigation of DR1-co-MMA yielded similar results. ${ }^{13} \mathrm{~A}$ higher $T_{g}$ is generally a positive development as it corresponds to a lower relaxation time $\tau$ at the working temperature and therefore a longer time at which the polarization can be maintained. ${ }^{7}$

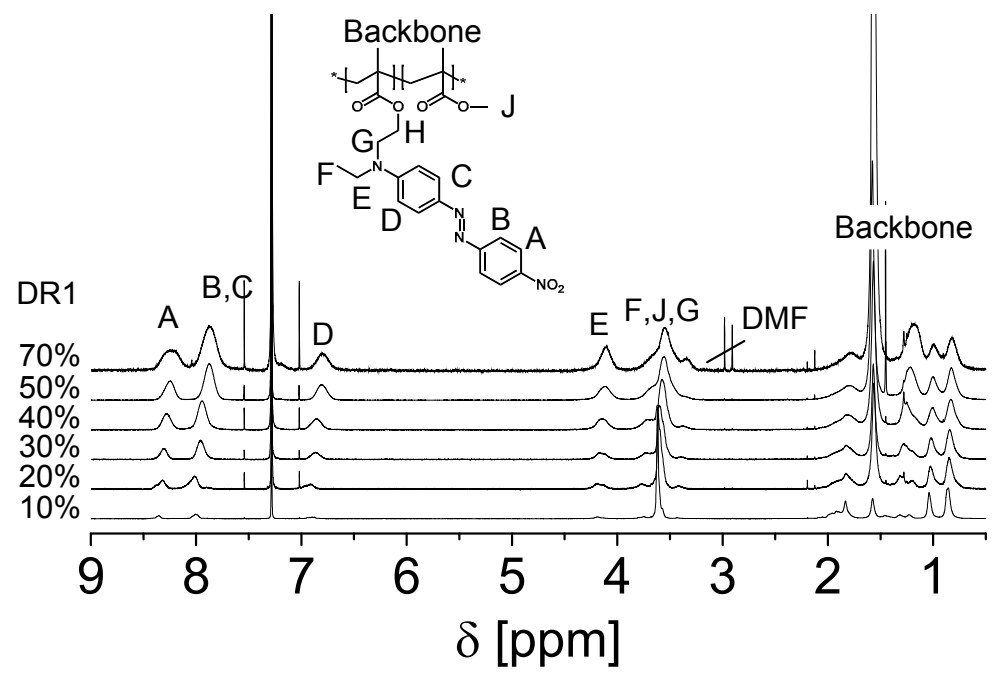

Figure 2. ${ }^{1} \mathrm{H}$ NMR spectra of DR1-co-MMA in $\mathrm{CDCl}_{3}$. All samples were normalized by the last backbone peak. The DR1 content increases from bottom to top. The crossed out peaks are solvent peaks.

\subsection{Impedance spectroscopy}

Impedance data were analysed using the phenomenological Havriliak-Negami function ${ }^{17}$

$$
\varepsilon^{*}=\varepsilon_{\infty}+i \frac{\sigma}{\varepsilon_{0} \omega}+\sum \frac{\Delta \varepsilon_{n}}{\left\{1+\left[i \omega \tau_{n}\right]^{1-\alpha_{n}}\right\}^{\beta_{n}}}
$$

, where $\varepsilon^{*}$ is the relative permittivity, $\varepsilon_{\infty}$ its high frequency limit, $\sigma$ the dc-conductivity, and $\varepsilon_{0}$ the vacuum permittivity. The sum (running over the index $n$ ) includes polarization contributions from different independent processes or subsystems. $\Delta \varepsilon_{n}$ and $\tau_{n}$ are the relaxation strengths and characteristic times. The parameters $\alpha_{n}$ and $\beta_{n}$ describe the width and asymmetry of the corresponding dielectric loss peak.

Figure 3 shows the real $\left(\varepsilon^{\prime}\right)$ and imaginary ( $\left.\varepsilon^{\prime \prime}\right)$ part of the permittivity $\left(\varepsilon^{*}\right)$ of DR1(10\%)-co-MMA, DR1(30\%)-coMMA, DR1(50\%)-co-MMA and DR1(70\%)-co-MMA (dots) at temperatures above $140^{\circ} \mathrm{C}$, together with the $\mathrm{HN}$-fit (line) with the fitting parameters for $150^{\circ} \mathrm{C}$ and $180^{\circ} \mathrm{C}$ visible in Table 3and 4 . In all plots there is a main peak in the imaginary spectrum corresponding to the dipole relaxation. 

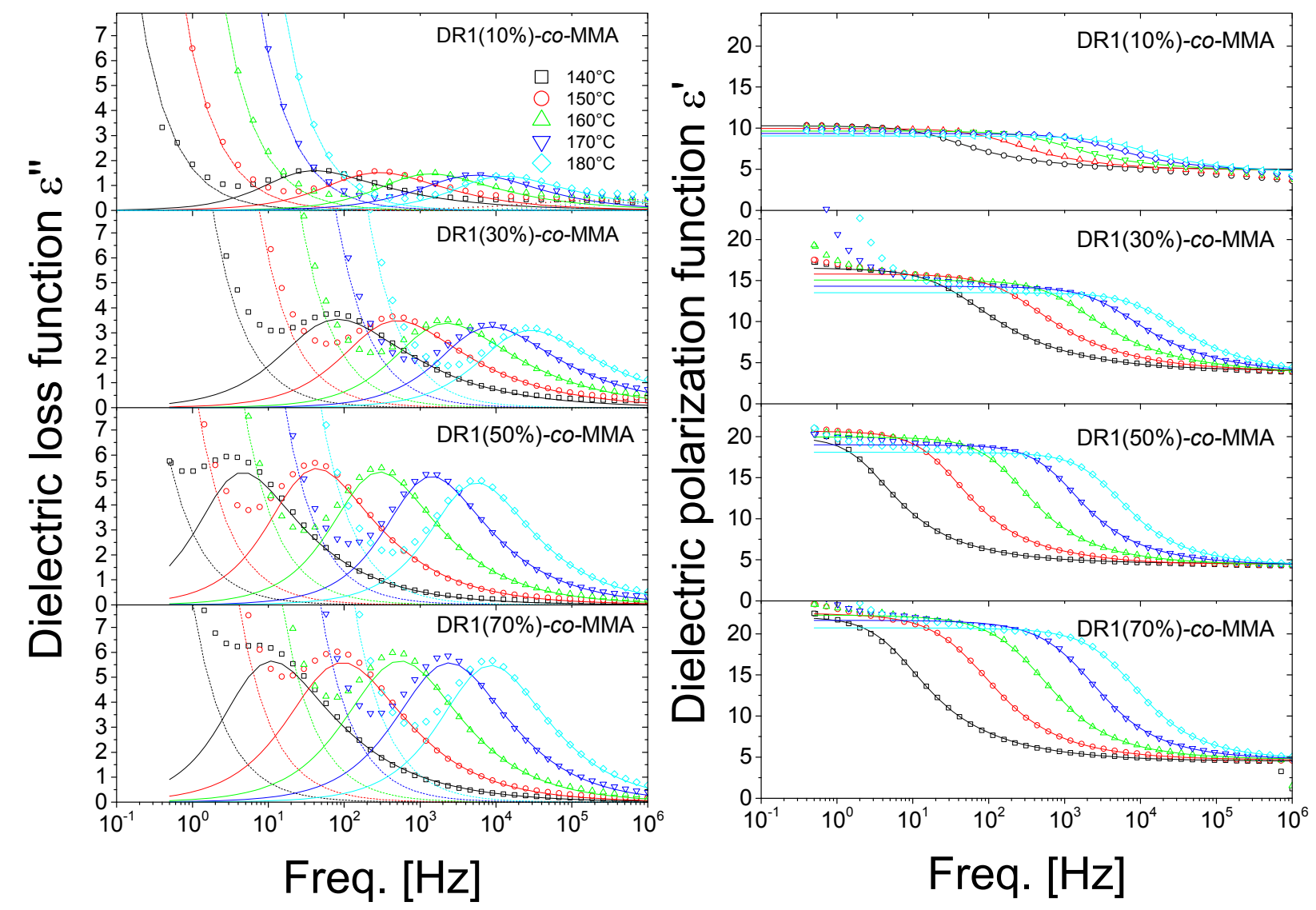

Figure 3. Imaginary ( $\left.\varepsilon^{\prime \prime}\right)$ and real part of the permittivity ( $\left.\varepsilon^{\prime}\right)$ of DR1-co-MMA samples (open symbols) at $140^{\circ} \mathrm{C}$ to $180^{\circ} \mathrm{C}$ and the HN fit (lines).

The relaxation strength $\Delta \varepsilon$ increases with the amount of DR1 in the copolymer from 5 to 18 . A shoulder in the high frequency regime to the main peak is visible in the spectra of DR1(10\%)-co-MMA which can be attributed to the relaxation of the MMA repeating unit. ${ }^{18,19}$ MMA was previously found to have a relaxation strength $\Delta \varepsilon$, MMA of 3.7 at $125^{\circ} \mathrm{C} .{ }^{10}$ In DR1(10\%)-co-MMA the relaxation strength is $\Delta \varepsilon$, MMA $=1.6$. Lower relaxation strength in the copolymer is expected due to the lower content of MMA, but interactions with the DR1 could certainly play a role in lowering the relaxation strength to $43 \%$ of the value of the base material. The temperature dependence of $\varepsilon^{\prime}$ at $5 \mathrm{~Hz}$ is plotted in Figure 4. It can be seen, that DR1 units only respond significantly to electric fields above the $T_{g}$ of the copolymers, justifying a poling temperature in this range.

Table 3. high frequency limit permittivity $\varepsilon_{\infty}$ and relaxation strength $\Delta \varepsilon$ as determined by the HN-fit for DR1-co-MMA at $150^{\circ} \mathrm{C}$ and $180^{\circ} \mathrm{C}$ together with the standard error.

\begin{tabular}{|c|c|c|c|c|c|}
\hline \multirow{2}{*}{ Name } & \multirow{2}{*}{ Peak } & \multicolumn{2}{|c|}{$\varepsilon_{\infty}$} & \multicolumn{2}{|c|}{$\Delta \varepsilon$} \\
\hline & & $150{ }^{\circ} \mathrm{C}$ & $180^{\circ} \mathrm{C}$ & $150^{\circ} \mathrm{C}$ & $180^{\circ} \mathrm{C}$ \\
\hline \multirow{2}{*}{ DR1(10\%)-co-MMA } & MMA & - & - & $1.6 \pm 0.18$ & $0.55 \pm 0.21$ \\
\hline & DR1 & $3.4 \pm 0.22$ & $4.0 \pm 0.27$ & $5.0 \pm 0.18$ & $4.5 \pm 0.31$ \\
\hline DR1(30\%)-co-MMA & DR1 & $3.8 \pm 0.03$ & $3.1 \pm 0.06$ & $12.0 \pm 0.04$ & $10.4 \pm 0.06$ \\
\hline DR1(50\%)-co-MMA & DR1 & $4.4 \pm 0.02$ & $4.2 \pm 0.04$ & $16.3 \pm 0.04$ & $13.8 \pm 0.05$ \\
\hline DR1(70\%)-co-MMA & DR1 & $4.6 \pm 0.03$ & $4.7 \pm 0.09$ & $17.9 \pm 0.05$ & $16.1 \pm 0.10$ \\
\hline
\end{tabular}

Parameters $\alpha$ and $\beta$ given in Table 4 indicate that in all cases, except for the MMA, the dipolar dynamic is fundamentally different to that of independent dipoles described by Debye's model. 
Table 4. Shape parameters $\alpha, \beta$ and characteristic time $\tau$ as determined by the $\mathrm{HN}$-fit for DR1-co-MMA at $150^{\circ} \mathrm{C}$ and $180^{\circ} \mathrm{C}$ together with the standard error

\begin{tabular}{|c|c|c|c|c|c|c|c|}
\hline \multirow{2}{*}{ Name } & \multirow{2}{*}{ Peak } & \multicolumn{2}{|c|}{$\alpha$} & \multicolumn{2}{|c|}{$\boldsymbol{\beta}$} & \multicolumn{2}{|c|}{$\tau$} \\
\hline & & $150^{\circ} \mathrm{C}$ & $180^{\circ} \mathrm{C}$ & $150^{\circ} \mathrm{C}$ & $180^{\circ} \mathrm{C}$ & $150^{\circ} \mathrm{C}$ & $180^{\circ} \mathrm{C}$ \\
\hline \multirow{2}{*}{ DR1(10\%)-co-MMA } & MMA & $\overline{0.38 \pm 0.14}$ & $0 \pm 0.29$ & $1 \pm 0.94$ & $1 \pm 1.39$ & $6.7 \times 10^{-7} \pm 8.5 \times 10^{-7}$ & $2.4 \times 10^{-7} \pm 2.6 \times 10^{-7}$ \\
\hline & DR1 & $0.20 \pm 0.02$ & $0.11 \pm 0.02$ & $0.65 \pm 0.05$ & $0.51 \pm 0.09$ & $8.8 \times 10^{-4} \pm 9.8 \times 10^{-5}$ & $2.3 \times 10^{-5} \pm 2.9 \times 10^{-6}$ \\
\hline DR1(30\%)-co-MMA & DR1 & $0.16 \pm 0.01$ & $0.13 \pm 0.01$ & $0.53 \pm 0.01$ & $0.52 \pm 0.02$ & $6.1 \times 10^{-4} \pm 1.5 \times 10^{-5}$ & $1.1 \times 10^{-5} \pm 3.9 \times 10^{-7}$ \\
\hline DR1(50\%)-co-MMA & DR1 & $0.10 \pm 0.01$ & $0.10 \pm 0.01$ & $0.59 \pm 0.01$ & $0.66 \pm 0.02$ & $6.0 \times 10^{-3} \pm 1.1 \times 10^{-4}$ & $4.2 \times 10^{-5} \pm 1.3 \times 10^{-6}$ \\
\hline DR1(70\%)-co-MMA & DR1 & $0.20 \pm 0.01$ & $0.16 \pm 0.01$ & $0.70 \pm 0.02$ & $0.74 \pm 0.03$ & $2.5 \times 10^{-3} \pm 8.2 \times 10^{-5}$ & $2.5 \times 10^{-5} \pm 1.6 \times 10^{-6}$ \\
\hline
\end{tabular}

The standard errors for the fitting parameters for MMA are very high, due to the fact that the peak is very near the high end of the measured frequency spectrum and heavily covered by the DR1 peak. Any interpretation of the relaxation of MMA in this sample should take this into account. Values of $(1-\alpha) \beta<1$ are an indication of significant correlation between the dipoles, implying a non-exponential decay of any induced polarization. As a matter of fact, the relaxation dynamic would be exponential only for $\beta=1$ and $\alpha=0$. For $\alpha=0$ and $\beta<1$, the depolarization is described approximately by a stretched exponential, which does not seem to occur here for any of the presented cases.

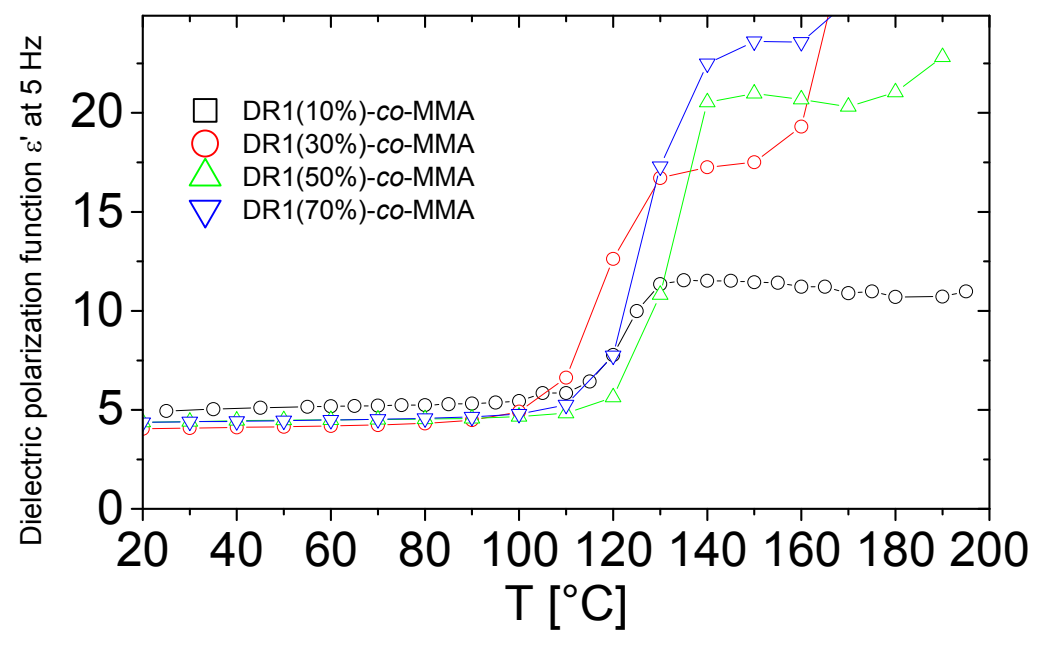

Figure 4. Real part of the permittivity ( $\left.\varepsilon^{\prime}\right)$ of copolymer samples at $0.5 \mathrm{~Hz}$ from $20^{\circ} \mathrm{C}$ to $180^{\circ} \mathrm{C}$.

Instead, the observed $\alpha>0$ is a conclusive evidence for a glassy dynamics; meaning that the polarization will display a power-law decay, $P(t) \propto(t / \tau)^{\alpha-2}$ for long observation times. ${ }^{20}$ Technically speaking, the parameter $\tau$ does not have a meaning of relaxation time here. For the power-law decays, the relaxation time diverges, which is characteristic for glassy systems. As a result, the induce polarization will display a very slow decay, which may be beneficial for certain applications and detrimental for others. It should be noted that we are referring in this paragraph to a glassy dynamics of the dipoles, and it should not be confused with the structural-glass transition that seem to take places for the polymer at lower temperatures $\left(\sim 125^{\circ} \mathrm{C}\right)$. We are currently performing experiments to further investigate the changes in the dielectric-glass behavior as the structural-glass transition is approached.

\subsection{Thermally stimulated depolarization current (TSDC)}

The short circuit TSDC measurement of DR1(10\%)-co-MMA and DR1(50\%)-co-MMA poled at $30 \mathrm{~V} / \mu \mathrm{m}$ and $120^{\circ} \mathrm{C}$ can be seen in Figure 5.30 V/ $\mu \mathrm{m}$ is much lower than the dielectric breakdown strength of the materials and was chosen based on the lowest field at which breakthrough occurred for any sample. While it was possible to pole DR1(10\%)-coMMA at up to $50 \mathrm{~V} / \mu \mathrm{m}$, samples with higher dipole content could only be poled at $30 \mathrm{~V} / \mu \mathrm{m}$. The reason for the higher 
breakdown strength in DR1(10\%)-co-MMA is not examined in detail, though a higher defect density in films with more dipoles could be a reason, as nice, flat films of such copolymers were more difficult to spincoat.

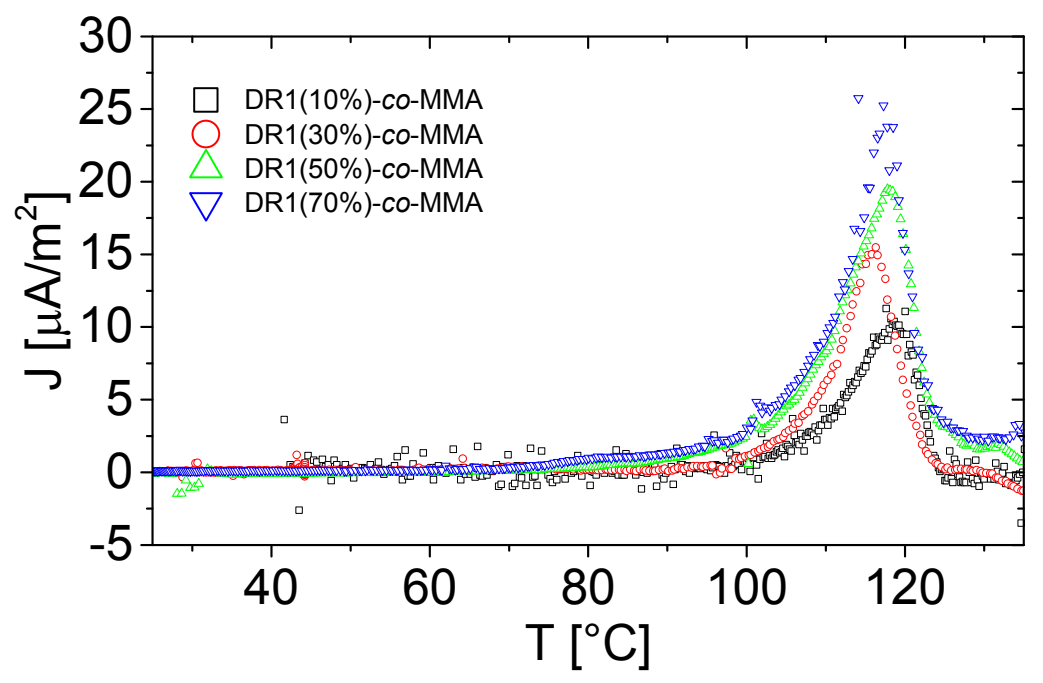

Figure 5. TSD current responses of the copolymer samples poled at $30 \mathrm{~V} / \mu \mathrm{m}$.

The polarization is stable at room temperature as evidenced by the current being nearly 0 between $25{ }^{\circ} \mathrm{C}$ and $80{ }^{\circ} \mathrm{C}$, supporting the finding of other authors, that the poled structure of DR1-co-MMA is stable for at least $60 \mathrm{~h}$ under certain conditions. ${ }^{13}$ The total polarizations of the samples by integration of the currents are $1.6 \mathrm{mC} / \mathrm{m}^{2}, 2.7 \mathrm{mC} / \mathrm{m}^{2}, 3.5 \mathrm{mC} / \mathrm{m}^{2}$ and $4.4 \mathrm{mC} / \mathrm{m}^{2}$ respectively. The relaxation strength can be calculated using ${ }^{21}$

$$
P=\varepsilon_{0} \Delta \varepsilon(T) E_{p},
$$

, $E_{p}$ being the poling field and $T_{p}$ the poling temperature, assuming that the system is quenched fast enough so that $\Delta \varepsilon$ corresponds to the value at the temperature it was poled. As the system was cooled down at a constant rate in this case, an exact determination of the temperature at which the dipoles were frozen is not possible. It will nonetheless have a value close to the one at $T_{p}$ as the copolymers have been poled at a temperature below $T_{g}$. At that temperature the relaxation dynamics of the dipoles is expected to be sufficiently slow to make the approximation to equation 2 tenable.

Table 5. The polarization of samples poled at a field of $30 \mathrm{~V} / \mu \mathrm{m}$ measured with TSDC compared with the relaxation strength $\Delta \varepsilon$ obtained by impedance spectroscopy (IS) at $150^{\circ} \mathrm{C}$.

\begin{tabular}{|c|c|c|c|c|}
\hline \multirow{2}{*}{ Name } & \multirow{2}{*}{$\frac{\text { Poling field }}{[\mathbf{V} / \boldsymbol{\mu m}]}$} & \multirow{2}{*}{$\begin{array}{c}\text { Polarization } \\
{[\mathrm{mC} / \mathrm{m} 2]} \\
\end{array}$} & \multicolumn{2}{|c|}{$\Delta \varepsilon$} \\
\hline & & & IS & TSDC \\
\hline DR1(10\%)-co-MMA & 30 & 1.6 & 5 & 4.5 \\
\hline DR1(30\%)-co-MMA & 30 & 2.7 & 12.0 & 10.2 \\
\hline DR1(50\%)-co-MMA & 30 & 3.5 & 16.3 & 15.1 \\
\hline DR1(70\%)-co-MMA & 30 & 4.4 & 17.8 & 16.4 \\
\hline
\end{tabular}


The calculated relaxation strengths are noted in Table 5 and are slightly lower than the values obtained from impedance spectroscopy at $150^{\circ} \mathrm{C}$. It is possible that the poling time of 10 min was too short. Studies with similar polymers have shown that when compared with impedance data, higher polarizations can be obtained when the poling time was optimized. ${ }^{11}$ The fact that the values are very near each other confirms though, that the freezing of the induced polarization was effective, and the achievable polarization can be estimated using the relaxation strength obtained from the impedance data not far above the structural-glass transition.

\section{CONCLUSIONS}

The impedance data of DR1-co-MMA was fitted with the Havriliak Negami equation and relevant parameters were extracted concerning the relaxation behaviour of the copolymer. By analysing the shape parameters $\alpha$ and $\beta$ the decay of the polarization induced by the DR1 sidegroup could be described quantitatively at temperatures higher than $T_{g}$. The lack of a TSD current at room temperature confirms previous findings that the poled structure is stable at room temperature and that the polarization of the sample can be accurately estimated using impedance spectroscopic data from temperatures above $T_{g}$. These results provide an overview of the poling behaviour of DR1-co-MMA and can be used to further study the materials in other systems. In a further step, the changes in the dielectric-glass behavior as the structural-glass transition is approached will be investigated. This will facilitate a better understanding of the relaxation behavior of the copolymer around the temperatures relevant to poling and can be used to optimize the poling procedure.

\section{ACKNOWLEDGEMENTS}

We gratefully acknowledge B. Fischer for the DSC measurements. We also gratefully acknowledge Swiss National Science Foundation (200021L_140577/1), the Swiss Federal Laboratories for Materials Science and Technology Empa for Financial support, and funding from the SCCER storage and mobility projects.

\section{REFERENCES}

[1] Dalton, L. R., Sullivan, P. A., Bale, D. H., "Electric field poled organic electro-optic materials: State of the art and future prospects," Chem. Rev. 110(1), 25-55 (2010).

[2] Enami, Y., Derose, C. T., Mathine, D., Loychik, C., Greenlee, C., Norwood, R. a., Kim, T. D., Luo, J., Tian, Y., et al., "Hybrid polymer/sol-gel waveguide modulators with exceptionally large electro-optic coefficients," Nat. Photonics 1(3), 180-185 (2007).

[3] Lin, C.-Y., Wang, A. X., Lee, B. S., Zhang, X.., Chen, R. T., "High dynamic range electric field sensor for electromagnetic pulse detection," Opt. Express 19(18), 17372 (2011).

[4] Seo, B. J., Kim, S., Fetterman, H., Steier, W., Jin, D.., Dinu, R., "Design of ring resonators using electro-optic polymer waveguides," J. Phys. Chem. C 112(21), 7953-7958 (2008).

[5] Ding, R., Baehr-Jones, T., Liu, Y., Bojko, R., Witzens, J., Huang, S., Luo, J., Benight, S., Sullivan, P., et al., “A low $\mathrm{V} \pi \mathrm{L}$ modulator with $\mathrm{GHz}$ bandwidth based on an electro-optic polymer-clad silicon slot waveguide," IEEE Int. Conf. Gr. IV Photonics GFP 18(15), 201-203 (2010).

[6] Burland, D. M., Miller, R. D., Walsh, C. A., "Second-order nonlinearity in poled-polymer systems," Chem. Rev. 94(1), 31-75 (1994).

[7] Bauer, S., "Poled polymers for sensors and photonic applications," J. Appl. Phys. 80(10), 5531 (1996).

[8] Hoffman, R. C., Pritchett, T. M., Orlicki, J. a., Dougherty, J. M., Lambeth, R. H., Rawlett, A. M., Herman, W. N., Park, D. H., "High-voltage poling of bulk guest-host polymers," ACS Symp. Ser. 1039, 97-109 (2010).

[9] Mo, X., Kinemura, K., Yamada, T., Otomo, A., Taguchi, D., Manaka, T.., Iwamoto, M., "Evaluation of thermal stability of electro-optic polymer by thermally stimulated depolarization current measurement," Jpn. J. Appl. Phys. 53, 1-5 (2014).

[10] Lei, D., Runt, J., Safari, A., Newnham, R. E., "Dielectric properties of azo dye-poly(methyl methacrylate) mixtures," Macromolecules 20(8), 1797-1801 (1987).

[11] Ren, W., Bauer, S., Yilmaz, S., Wirges, W., Gerhard-Multhaupt, R., "Optimized poling of nonlinear optical polymers based on dipole-orientation and dipole-relaxation studies," J. Appl. Phys. 75(11), 7211 (1994).

[12] Bauer, S., Bauer-Gogonea, S., Ploss, B.,"Nonlinear dielectric response of poled amorphous polymer dipole glasses,” J. Non. Cryst. Solids 351(33-36), 2759-2763 (2005). 
[13] Nahata, A., Shan, J., Yardley, J. T.., Wu, C., "Electro-optic determination of the nonlinear-optical properties of a covalently functionalized Disperse Red 1 copolymer," J. Opt. Soc. Am. B 10(9), 1553 (1993).

[14] Li, N., Lu, J., Xia, X., Xu, Q., Wang, L., "Synthesis and the third-order nonlinear optical properties of soluble polymers with different substituted azobenzene side chains," Polymer (Guildf). 50(2), 428-433, Elsevier Ltd (2009).

[15] Mopsik, F. I., Broadhurst, M. G., "Molecular dipole electrets,” J. Appl. Phys. 46(10), 4204 (1975).

[16] Haynes, W. M., CRC Handbook of Chemistry and Physics, 96th ed., William M. Haynes, Ed., Taylor \& Francis, New York (2015).

[17] Havriliak, S., Negami, S., "A complex plane representation of dielectric and mechanical relaxation processes in some polymers," Polymer 8, 161-210 (1967).

[18] Bergman, R., Alvarez, F., Alegría, a.., Colmenero, J., "The merging of the dielectric $\alpha$ - And $\beta$-relaxations in poly-(methyl methacrylate)," J. Chem. Phys. 109(17), 7546-7555 (1998).

[19] Seki, Y., Kita, R., Shinyashiki, N., Yagihara, S., Yoneyama, M., "Molecular dynamics of poly(methyl methacrylate) determined by dielectric relaxation spectroscopy," AIP Conf. Proc. 469, 466-469 (2013).

[20] Cuervo-Reyes, E., private communication of a submitted paper

[21] Onsager, L., "Electric moments of molecules in liquids," J. Am. Chem. Soc. 58, 1486-1493 (1936). 